\title{
Influence of journal bearing axial grooves on the dynamic behavior of horizontal rotors
}

\author{
Miguel Angelo de Carvalho Michalski ${ }^{\mathrm{a}, *}$, Moysés Zindeluk ${ }^{\mathrm{b}}$ and Renato de Oliveira Rocha ${ }^{\mathrm{a}}$ \\ ${ }^{a}$ Cepel, Centro de Pesquisa em Energia Elétrica, Av. Jequitibá s/n. Cidade Universitária, Ilha do Fundão, Rio de \\ Janeiro, RJ, CEP: 21944-970, Brazil \\ ${ }^{\mathrm{b}}$ COPPE/UFRJ, LAVI, Sala I-130, Centro de Tecnologia, Av. Jequitibá s/n, Cidade Universitária, Ilha do Fundão, \\ Rio de Janeiro, RJ, CEP: 21945-970, Brazil
}

\begin{abstract}
Journal bearing design and the lubricant characteristics are very influential in a rotating machine behaviour. The bearing geometry can drastically affect the lubricant flow and also the rotor dynamics. Approaching that issue, this paper presents an experimental study of the dynamic behavior of a horizontal rotor suported by journal bearings with semi-circular axial grooves. The journal bearings were manufactured with a varied number of axial grooves and a versatile test rig is used, making possible the analysis of different configurations. The acquired signals are analyzed with classical and non-linear tools and the differences among the rotors' configurations can be shown.
\end{abstract}

Keywords: Rotordynamics, grooved journal bearings, journal bearing instabilities, non-linear dynamics

\section{Introduction}

The combination of vibration and structural dynamics with hydrodynamic analysis brings up a great number of phenomena that deserve detailed investigation. In some cases, the models for numerical solutions are very well developed. In addition, a great number of experiments have been done and new experiments can suggest new ideas or simply confirm the theory.

The basic rotor elements are the shaft, the disks and the bearings [6]. The disks are generally modeled as rigid bodies, and participate only in the kinetic energy of the system. The shaft can be represented by a beam and is characterized by strain and kinetic energies or, in simpler models considering the shaft as rigid as the disk, only the kinetic energy is taken into account. Bearings add flexibility and viscous terms, assumed as known. Alternatively, they can also be modeled as external forces on the system.

Fluid film bearings can be usefully classified in terms of their rotor support mechanism, for the turbomachinery design analysis, monitoring and diagnosis or troubleshooting purpose [11]. The major categories of fluid film bearings can be classified as hydrostatic or hydrodynamic.

Both types need a fluid supply pressure, but in the second group, this pressure only needs to be high enough to maintain an ample supply of lubricant to the load-supporting clearance around the journal. The fluid support pressure is generated only by the motion of the journal and depends on the fluid viscosity. In insufficient fluid supply cases, the rotor works under boundary, or starved (also known as pour) lubrication. This can happen in some small mechanisms or in some particular situations of industrial turbomachinery [10]. The experimental model described in this paper uses journal bearings working under hydrodynamic lubrication. In this case, the lubricant supply is considered sufficient to prevent contact between the journal and the bearing surfaces.

The contracting oil film necessary to generate the pressure is obtained by a small lateral shift in the shaft or journal [9]. In Fig. 1 an example of pressure field generation is given in a plain journal bearing. In this case, $e$ 


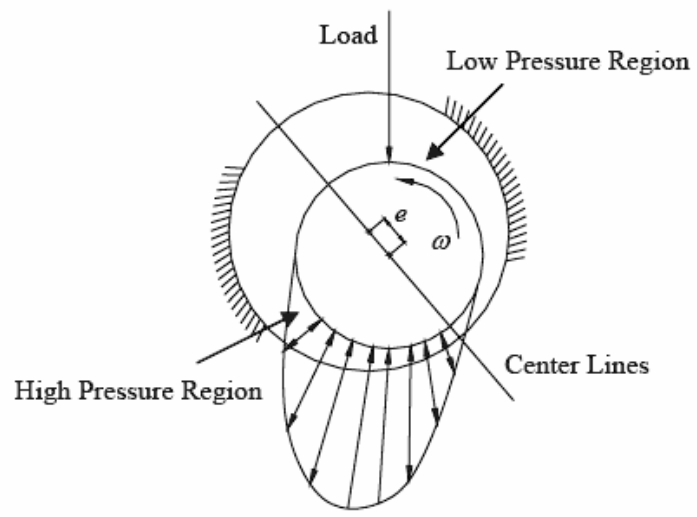

Fig. 1. Pressure field generated in a plain journal bearing.

represents the eccentricity between the shaft center and the bearing center (in other words, the lateral shift of the shaft) and $\omega$ the rotor rotational speed.

The lubricant fluid is pulled by viscous shear into the high-pressure region produced by the journal eccentricity. The rotation of the journal (or bearing) induces the viscous shear, producing a relative velocity along the film wall. In the high-pressure region, the fluid pressure rises, while in the low-pressure region, it decreases. The distribution of hydrodynamic pressure around the journal produces a force that reacts to the applied load. If for some reason this force equilibrium is lost, the rotor jumps to an unstable condition.

Considering the bearing design, different models, from the simple plain bearing to sophisticated tilting pad journal bearings, can be found. The variety of models can solve problems of oil instabilities, very common in rotor machines with light loaded plain journal bearing. The use of grooves in the bearings, for example, tries to avoid this kind of problem.

Generally, the numerical problem is to find the pressure field between the journal and the bearing and then the stiffness and damping coefficients. A derivation of a version of the Reynolds' equation is used to define the pressure field within a bearing as a function of its motion [2]. In the next section, this equation will be introduced and discussed.

\section{The pressure field mathematical model}

In order to build a mathematical model, some simplifying standard assumptions are made with respect to the journal bearing, as a basis for Reynolds' equation [5] and [9].

(a) Newton linear viscous model holds for the lubricant.

(b) The inertia effects of the lubricant can be neglected.

(c) Body forces can be neglected (the weight of the fluid in the film is small in comparison to the other acting forces).

(d) The lubricant is incompressible and the pressure across the film is constant.

(e) The density of the fluid is constant.

(f) Viscosity of the lubricant is constant throughout the film, considering that the fluid temperature remains constant.

(g) The film curvature with respect to the thickness can be neglected.

*Corresponding author. Tel.: +55 212598 6496; E-mail: mich@ cepel.br. 


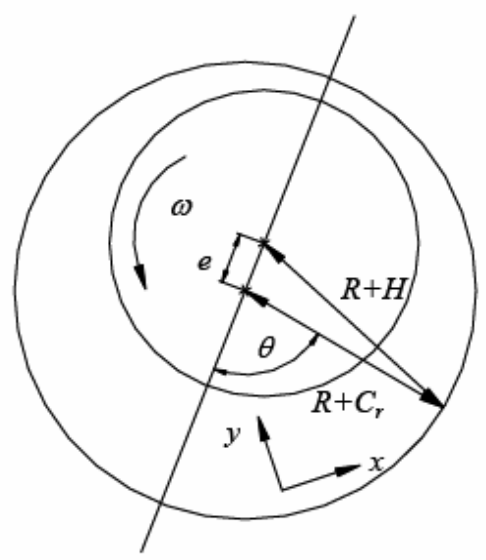

Fig. 2. Plain journal bearing geometry.

In Fig. 2, it is shown a plain journal bearing geometry and it is possible to see the referential that follows the fluid, present in Eq. (1). In addition, two new terms are given: $R$, the radius of the bearing and $C_{r}$, the radial clearance. Considering also that $H$ is the film thickness, $P$ is the pressure field, $r$ is the shaft radius and $\mu$ is the fluid viscosity, Reynolds' equation is presented, in the form:

$$
\frac{\partial}{\partial x}\left(H^{3} \frac{\partial P}{\partial x}\right)+\frac{\partial}{\partial y}\left(H^{3} \frac{\partial P}{\partial y}\right)=12 \mu\left(\frac{\omega r}{2} \frac{\partial H}{\partial x}+\frac{\partial H}{\partial t}\right)
$$

Circumferential coordinates are more suitable for the journal bearings analysis. Reynolds' equation is represented in these new coordinates considering that the circumferential variable $x$ is replaced by $R \theta$ The angle $\theta$ is illustrated in Fig. 2 and it is a counterclockwise rotation originated at the centers line. By this way, Eq. (1) can be expressed as:

$$
\frac{1}{R^{2}} \frac{\partial}{\partial \theta}\left(H^{3} \frac{\partial P}{\partial \theta}\right)+\frac{\partial}{\partial y}\left(H^{3} \frac{\partial P}{\partial y}\right)=12 \mu\left(\frac{1}{R} \frac{\omega r}{2} \frac{\partial H}{\partial \theta}+\frac{\partial H}{\partial t}\right)
$$

To obtain useful solutions, two successful alternative approaches can be employed: Reynolds' equation; simplification for special cases of practical interest, resulting in a functional solution; or the reformulation of the equation into finite-difference or finite-element form, resulting in a numerical solution [11].

In addition, two special limiting cases can be used: the Ocvirk Bearing Solution, for short bearings and the Sommerfeld Bearing Solution, for long bearings. In this work, the first case is used. The Ocvirk model gives a reasonably good definition of bearing-reaction direction but predicts an erroneously large magnitude. The error in the magnitude sharply increases for high eccentricity ratios [3]. In this case, the Reynolds' equation is simplified, represented by the Eq. (3).

$$
\frac{\partial}{\partial y}\left(H^{3} \frac{\partial P}{\partial y}\right)=12 \mu\left(\frac{1}{R} \frac{\omega r}{2} \frac{\partial H}{\partial \theta}+\frac{\partial H}{\partial t}\right)
$$

A direct integration in $y$ can render the equation solution [7], considering the pressure equal to zero in the bearing length limits and assuming its maximum value at the bearing center. Also, this work considers the G ümbel Boundary Conditions more appropriate, as the presence of negative pressures would not have a physical equivalence.

$$
P=3 \frac{\mu}{H^{3}}\left(2 \frac{\partial H}{\partial t}+\omega \frac{\partial H}{\partial \theta}\right)\left(y^{2}-\frac{L^{2}}{4}\right)
$$

At this point, for each bearing design, the equation has a different solution. To obtain the pressure field it is necessary to know the film thickness. Once the orbit inside the bearing and the bearing geometry are known, the thickness will be simply the difference between the geometry and the shaft periphery orbit.

To set an example of the theory, a general orbit is considered as a composition of two signals in phase of $90^{\circ}$ with one single frequency component found in each one. 
The equations used to trace the orbit are presented below, were $O$ is the shaft displacement inside de bearing, $r$ is the shaft radius, $o_{x}$ and $o_{z}$ are the distances to the equilibrium position (orbit center) from the bearing center line in the horizontal and vertical directions and $e_{x}$ and $e_{z}$ are the shaft effective displacement in the same directions.

$$
O(\theta, t)=r+\left(o_{x}+e_{x} \cos (2 \omega t)\right) \cos \theta+\left(o_{z}+e_{z} \sin (2 \omega t)\right) \sin \theta
$$

In another hand, the bearing geometry is given by the formulation below. Each bearing type has a different formula and $G_{i}(\theta)$ is the geometry in each case, where $i$ is the number of grooves in the bearing. The equations shown below belongs respectively to the plain journal bearing, the 3 grooved journal bearing and the 6 grooved journal bearing.

$$
\begin{aligned}
& G_{0}(\theta)=R \\
& G_{3}(\theta)=\left\{\begin{array}{l}
R+\frac{R}{10} \cos (12 \theta), \theta \in\left\{\left[-\frac{\pi}{24}, \frac{\pi}{24}\right],\left[\frac{5 \pi}{8}, \frac{17 \pi}{24}\right],\left[\frac{31 \pi}{24}, \frac{11 \pi}{8}\right]\right\} \\
R, \theta \in\left\{\left[\frac{\pi}{24}, \frac{5 \pi}{8}\right],\left[\frac{17 \pi}{24}, \frac{31 \pi}{24}\right],\left[\frac{11 \pi}{8}, \frac{47 \pi}{24}\right]\right\}
\end{array}\right. \\
& G_{6}(\theta)=\left\{\begin{array}{l}
R+\frac{R}{10} \cos (12 \theta), \theta \in\left\{\left[-\frac{\pi}{24}, \frac{\pi}{24}\right],\left[\frac{7 \pi}{24}, \frac{3 \pi}{8}\right],\left[\frac{5 \pi}{8}, \frac{17 \pi}{24}\right],\left[\frac{23 \pi}{24}, \frac{25 \pi}{24}\right],\left[\frac{31 \pi}{24}, \frac{11 \pi}{8}\right],\right. \\
R, \theta \in\left\{\left[\frac{\pi}{24}, \frac{7 \pi}{24}\right],\left[\frac{3 \pi}{8}, \frac{5 \pi}{8}\right],\left[\frac{17 \pi}{24}, \frac{23 \pi}{24}\right],\left[\frac{25 \pi}{24}, \frac{31 \pi}{24}\right],\left[\frac{11 \pi}{8}, \frac{13 \pi}{8}\right],\left[\frac{41 \pi}{24}, \frac{47 \pi}{24}\right]\right\}
\end{array}\right.
\end{aligned}
$$

Finally, the equation that determines the film thickness is given below.

$$
H=G_{i}(\theta)-O(\theta, t)
$$

In the numerical simulation, the frequency was set to $30 \mathrm{~Hz}$, so the rotor rotational speed considered was $1800 \mathrm{rpm}$. Considering the bearing geometry, the values assumed in the numerical simulation were: $o_{x}=0.015 \mathrm{~mm}, o_{z}=-$ $0.015 \mathrm{~mm}, e_{x}=0.025 \mathrm{~mm}, e_{z}=0.015 \mathrm{~mm}, R=4.05 \mathrm{~mm}, L=8.00 \mathrm{~mm}$ and $y=0 \mathrm{~mm}$ (the bearing center in the longitudinal direction). The grooves radius is in all cases $0.81 \mathrm{~mm}$, what means $10 \%$ of the bearing diameter. The grooves length is equal to the bearings, once the grooves totally cross the bearing in the longitudinal direction. The shaft radius was set to $r=4.00 \mathrm{~mm}$, so the journal bearing radial clearance is $0.1 \mathrm{~mm}$. The oil viscosity considered was $15 \mathrm{cSt}$.

As presented in Fig. 3, the pressure field in the center of the three different journal bearings functions of $\theta$.

In the second and third cases shown, with the grooves added to the journal bearings, pressure peaks appear, related to the positions of the semi-circular axial grooves, generating forces which are very concentrated in specific positions. These peaks follow low pressure areas, suggesting cavitation in the oil film. The effects of these peaks and valleys can be discussed with the experimental results.

\section{The experimental system}

The test rig used in this work was built in the Vibration and Acoustic Laboratory (LAVI) of COPPE/UFRJ [1]. The shaft and the disk are made in steel SAE 1045. The shaft total length is $800 \pm 1 \mathrm{~mm}$ and the diameter is 7.90 $\pm 0.05 \mathrm{~mm}$. The disk is fixed in the shaft center, with a distance of $250 \pm 1 \mathrm{~mm}$ from each bearing, which means something about $500 \mathrm{~mm}$ from one bearing to another in all cases; the disk diameter is $150,00 \pm 0.05 \mathrm{~mm}$ and the thickness is $15,00 \pm 0.05 \mathrm{~mm}$. The bearings were manufactured in bronze with the inside diameter of $8.10 \pm$ $0.05 \mathrm{~mm}$ and the length of $8.00 \pm 0.05 \mathrm{~mm}$. The radial clearance measured in all bearings was $0.10 \pm 0.05 \mathrm{~mm}$.

The bearings are placed in supports and two lids are used to lock each bearing inside the support. The oil is supplied from the top of each support and extracted from both lids, through flexible pipes. The oil used in the test rig is the Lubrax Industrial HR-32-EP (ISO Grade 32). The oil temperature during the acquisition period in the tests was $40^{\circ} \mathrm{C}$. The fluid properties are given below, in Fig. 4 . 

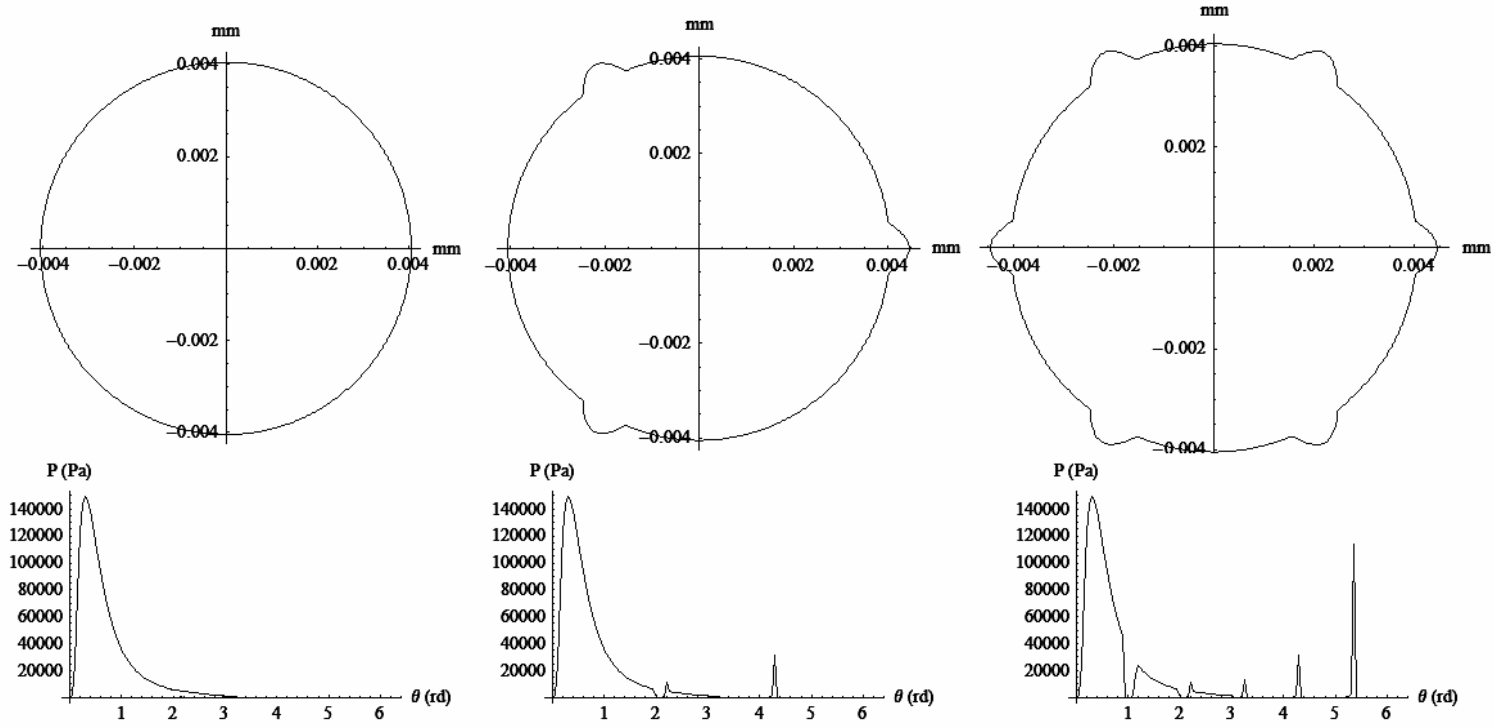

Fig. 3. Examples of orbits in different journal bearings and the corresponding pressure field.

\begin{tabular}{|c|c|c|c|c|c|c|c|c|c|}
\hline ISO GRADES & & 15 & 22 & 32 & 46 & 68 & 100 & 150 & 220 \\
\hline $\begin{array}{l}\text { Specific Gravity at } 20 / 4^{\circ} \mathrm{C} \\
\text { Flash Point (COC) } \\
\text { Pour Point } \\
\text { Viscosity at } 40^{\circ} \mathrm{C} \\
\text { Viscosity at } 100^{\circ} \mathrm{C} \\
\text { Viscosity Index } \\
\text { Total Acid Number } \\
\text { Demulsibility. 30min } \\
54.4^{\circ} \mathrm{C} \\
82{ }^{\circ} \mathrm{C} \\
\end{array}$ & $\begin{array}{l}\left({ }^{\circ} \mathrm{C}\right) \\
\left({ }^{\circ} \mathrm{C}\right) \\
(\mathrm{CSt}) \\
(\mathrm{CSt}) \\
(\mathrm{mgKOH} / \mathrm{g})\end{array}$ & \begin{tabular}{|c|}
0.8569 \\
198 \\
-33 \\
15.07 \\
3.56 \\
118 \\
0.70 \\
\\
pass \\
- \\
\end{tabular} & \begin{tabular}{|c|}
0.8594 \\
212 \\
-15 \\
20.8 \\
4.24 \\
108 \\
0.70 \\
\\
pass \\
- \\
\end{tabular} & \begin{tabular}{|c|}
0.8632 \\
232 \\
-21 \\
30.2 \\
5.38 \\
113 \\
0.70 \\
\\
pass \\
- \\
\end{tabular} & \begin{tabular}{|c|}
0.8686 \\
244 \\
-18 \\
44.3 \\
6.83 \\
110 \\
0.70 \\
\\
pass \\
- \\
\end{tabular} & \begin{tabular}{|c|}
0.8744 \\
260 \\
-18 \\
65.3 \\
8.77 \\
107 \\
0.70 \\
\\
pass \\
- \\
\end{tabular} & \begin{tabular}{|c|}
0.8796 \\
270 \\
-18 \\
94.9 \\
11.08 \\
103 \\
0.70 \\
\\
- \\
pass \\
10
\end{tabular} & \begin{tabular}{|c|}
0.8858 \\
274 \\
-12 \\
147.0 \\
14.82 \\
100 \\
0.70 \\
- \\
pass \\
10
\end{tabular} & \begin{tabular}{|c}
0.8920 \\
280 \\
-9 \\
217 \\
19.04 \\
99 \\
0.70 \\
\\
- \\
pass
\end{tabular} \\
\hline
\end{tabular}

November/00

Fig. 4. Oil properties.

The bearing supports are attached to a cast iron base that assures no misalignment between the bearings and it is considered an inertial reference to the rotor, as its vibration amplitude is much smaller than the rotor vibration amplitude. The base weighs about $170 \mathrm{kgf}$ and the rotor about $1.1 \mathrm{kgf}$. Therefore, the static load on each bearing is $5.5 \mathrm{~N}$. The system is driven by an electric motor (WEG $0.33 \mathrm{HP}$, two poles) and controlled by an AC converter (WEG ML-2.6/1AC. 200-240).

Inductive analogue sensors (Balluff BAW 018-PF-1-K) measure the disk orbit. Two of these sensors were perpendicularly positioned to the disk, in the radial direction, with $90^{\circ}$ between them. The sensors were calibrated in order to work in their linear range. An aluminum disk with a single hole positioned in the electric motor shaft triggers the signals. By this way all the signals are acquired considering the same start time. The experimental data was acquired using a laptop with NI DAQCard 6024E I/O for PCMIA (200 kS/s) associated with a connector block BNC-2110 and a shielded cable from National Instruments.

The acquisition frequency was $2048 \mathrm{~Hz}$ and the total number of points acquired was 20480, what means 10 seconds in the acquisition duration. The programs used to acquire and analyze the signals were developed in LabView. In order to eliminate transients, the first 400 points were discarded in each acquisition. The highest sampling frequency 

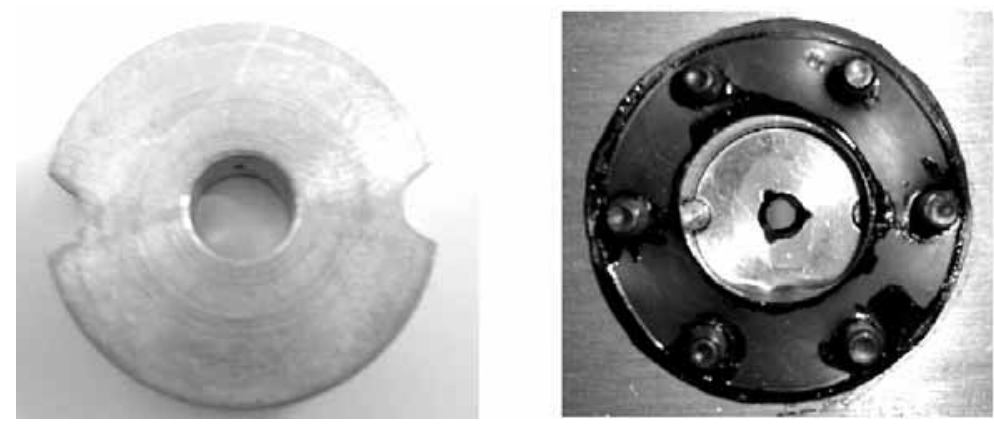

Fig. 5. Bearings.

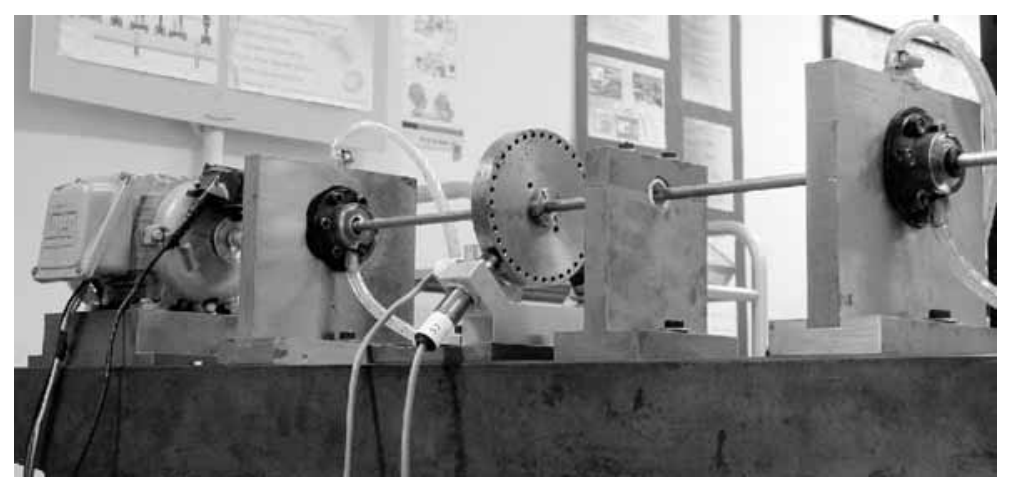

Fig. 6. Rotor general view.

considered was $300 \mathrm{~Hz}$. With the acquisition frequency used, there were no aliasing problems and no need of analogical filters. Each experimental test followed these conditions.

In Fig. 4, two bearings are illustrated. The first one is a plain journal bearing out of the support, and the second one, a journal bearing with three axial-grooves positioned in the support.

A general view of the rotor is presented in Fig. 5, with the sensors and the disk in evidence.

\section{Experimental results and analysis}

The first test results presented came from the machine run-up. The test was done from $0 \mathrm{~Hz}$ to $100 \mathrm{~Hz}$, during 10 seconds, programming the AC converter to linear acceleration ramp. The objective was to experimentally find the rotor first natural frequency. The first natural frequency is about $30 \mathrm{~Hz}(1800 \mathrm{rpm})$, as can be seen in Fig. 6.

The data acquisition for the other tests was performed under steady state at several rotational speeds. For each one of the three bearings used, the rotor ran from $5 \mathrm{~Hz}$ to $100 \mathrm{~Hz}$ in steps of $5 \mathrm{~Hz}$. The signals are filtered with a low pass filter in a frequency equivalent to three times the rotational speed. The differences between the cases can be observed with different kinds of signal analysis.

The analysis show a self-excited vibration of the system with a frequency near the first rotor natural frequency happening when no external forces are present (except for a very low unbalance, always present in the experiments) but an internal feedback mechanism transferring the rotational energy into vibrations, called oil whirl [8]. The oil film rotational average speed is close to half of the shaft rotational speed [7]. Therefore, when the rotor works with a frequency twice the first critical frequency, the oil film speed is almost at the first critical value, leading the rotor to a very unstable condition, called oil whip.

Analyzing the orbits, Figs 8, 9 and 10, in all cases it is possible to see that the first critical really appears near $30 \mathrm{~Hz}$. In the third case, the first critical seems to be, in fact, near $25 \mathrm{~Hz}$, what can be associated to a stiffness reduction. 


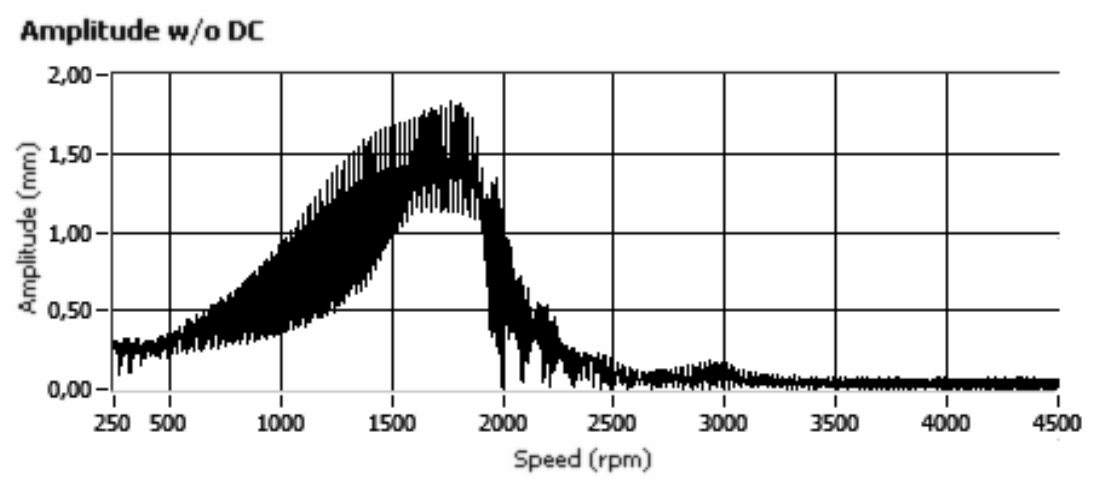

Fig. 7. Rotor run-up.

Above $45 \mathrm{~Hz}$ it is possible to see the oil whirl influence, especially with the 6 grooved journal bearing. In this case, above $50 \mathrm{~Hz}$ the groove influence is very strong in the rotor behavior: the orbit shape at $50 \mathrm{~Hz}$ is the same at $25 \mathrm{~Hz}$ but the phase between the major axes from each ellipse is 90 degrees. This shows that the natural frequency crossing had already happened (the rotor already passed through its first natural frequency) [6].

Also, the rotor with 3 axial grooves journal bearing only seems to have some influence on its behavior caused by the oil whirl at $55 \mathrm{~Hz}$, when the presence of a sub-harmonic corresponding to half the value of the rotational speed in the frequency spectrum is noticeable.

Above $60 \mathrm{~Hz}$, the rotors with grooved bearings seem to come to a stable condition, what means the whirl phenomenon disappears. However the rotor with plain journal bearings only achieves a stable condition above $85 \mathrm{~Hz}$. The orbit amplitude in this case does not significantly change, as in the experiment using the 3 grooved journal bearings. Analyzing the signal's FFT, Figs 11 and 12, in the two displacement directions (FFTx - horizontal direction and FFTz - vertical direction), it is possible to improve the conclusions.

Considering that the oil supply pressure and flow did not change from one bearing to another and the test speeds and conditions were the same, the presented differences in the rotor assemblies showed that the use of bearings with three axial groves gave the rotor the most stable condition. It is the least susceptible to the oil whirl, presenting a sub-harmonic in the frequency spectrum only when its rotational speed is near $55 \mathrm{~Hz}$. In the other way, the rotor with the plain bearing is the most unstable, been susceptible to the oil whirl from $45 \mathrm{~Hz}$ to $60 \mathrm{~Hz}$ and presenting the occurrence of oil whip from $60 \mathrm{~Hz}$ to almost $85 \mathrm{~Hz}$, when the sub-harmonic frequency is near $25 \mathrm{~Hz}$. The third rotor, with the 6 grooved journal bearings shows in its FFT only the oil whirl, from $45 \mathrm{~Hz}$ to $55 \mathrm{~Hz}$, but with a very strong influence at $50 \mathrm{~Hz}$.

Considering the Poincaré map, Figs 13, 14 and 15, as an alternative tool to the signal analysis, the rotors non-linear aspects can be better understood. The Poincaré map (or Poincaré section) is a procedure that allows the reduction of a continuous dynamic system in time into a discrete one [4]. This tool allows a better comprehension of the problem eliminating the time influence on the signal. In this case, the orbit of the rotor was considered quasi-periodic, one of the standard cases for attainment of the Poincaré map. The trigger signal was used to precisely determine the rotor rotational speed. This frequency was used to set up the Poincaré map derived from the disk orbit (resampling the displacement signal) once unbalance, synchronous to the rotational speed, was the only external force considered to act in the rotor.

Observing the maps, it is possible to notice that some bifurcations appear in the Poincar é map at the same rotational speeds that the oil whirl occurs. This can be explained considering the consequences that the oil whirl brings to the rotor behavior or, in other words, the sub-harmonic frequency that begins to influence the rotor dynamics.

The Poincaré section can add to the signal analysis new information and, furthermore, it can verify some previous conclusions. The rotor using the 3 grooved journal bearing is in fact the most stable, presenting a very single bifurcation when its rotational speed is $55 \mathrm{~Hz}$. The rotor using 6 grooved journal bearing is a little bit more unstable, presenting bifurcations in the Poincaré map from $45 \mathrm{~Hz}$ to $55 \mathrm{~Hz}$. At $50 \mathrm{~Hz}$, as expected considering the behavior very similar to the first forward natural frequency, the bifurcation is very noticeable. Finally, the rotor using plain journal bearings seems to be the most unstable case, presenting bifurcation in the Poincar é map between $45 \mathrm{~Hz}$ and 
Plain Bearing

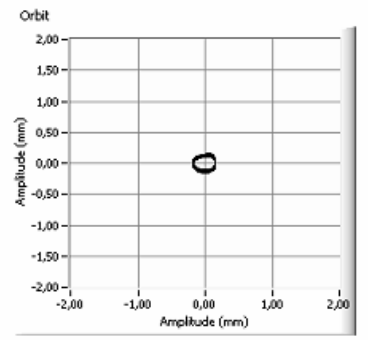

$10 \mathrm{~Hz}$

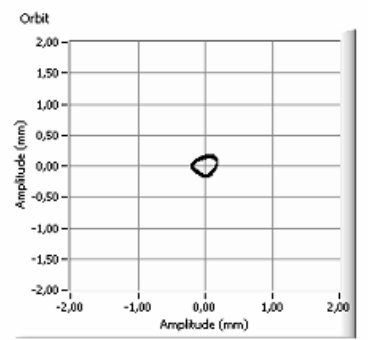

$20 \mathrm{~Hz}$

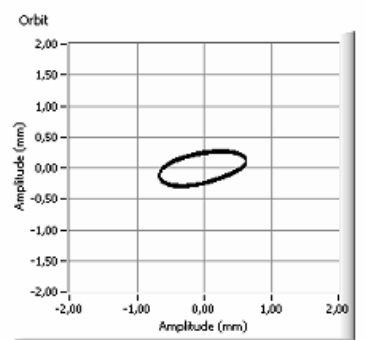

$25 \mathrm{~Hz}$

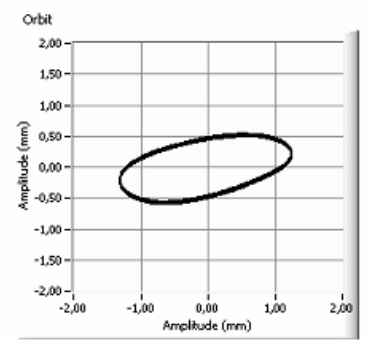

$30 \mathrm{~Hz}$

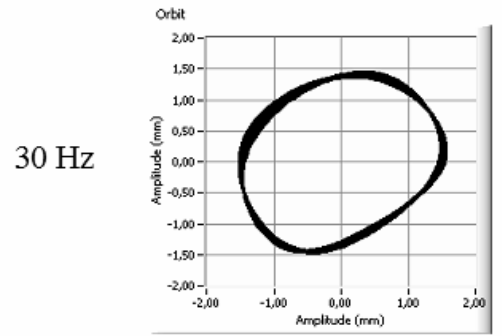

\section{Grooves Bearing}
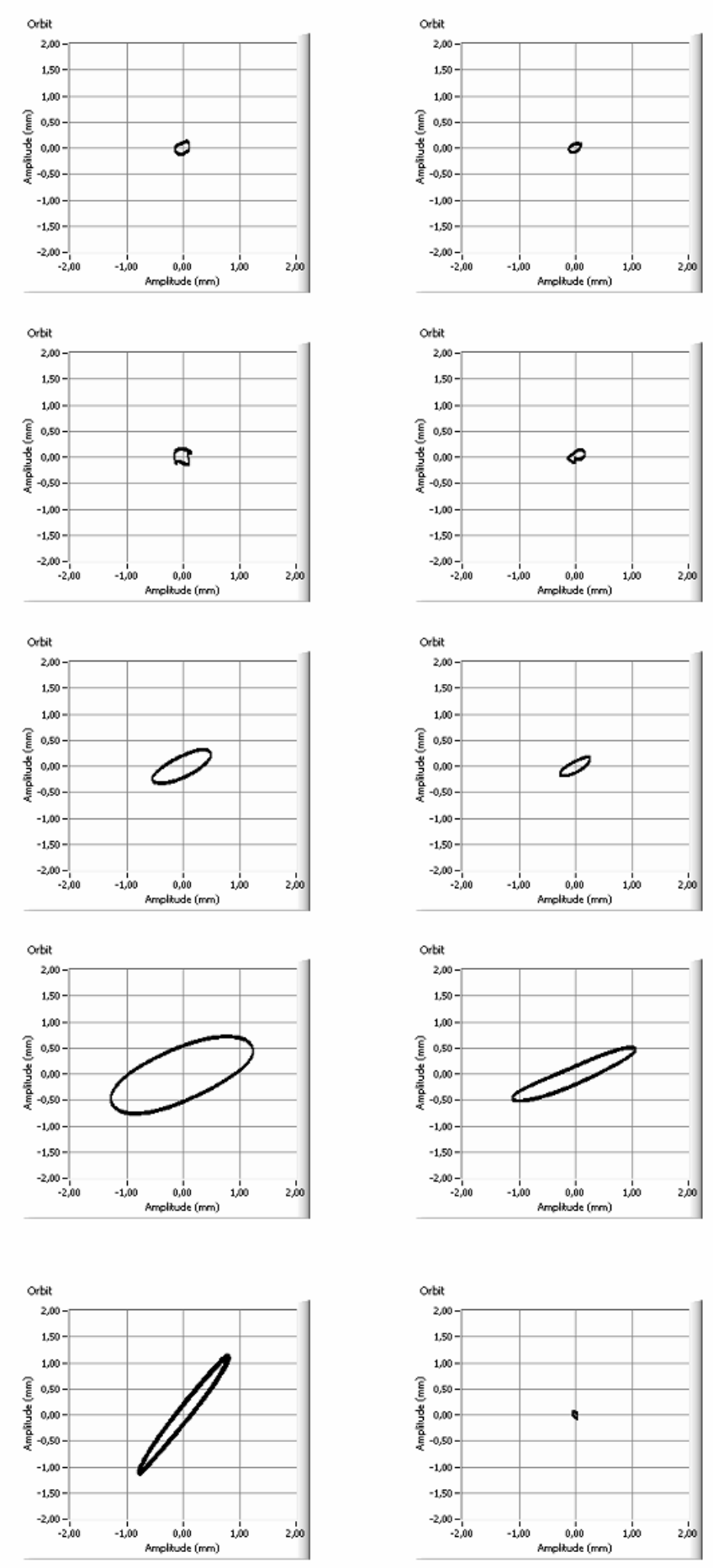

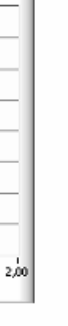

Fig. 8. Results - Orbit. 
$35 \mathrm{~Hz}$

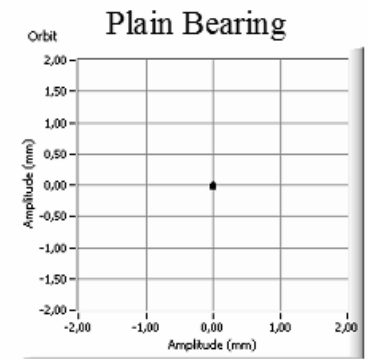

$45 \mathrm{~Hz}$

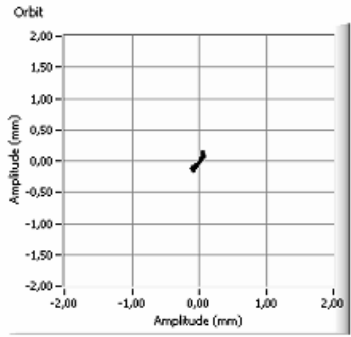

$50 \mathrm{~Hz}$

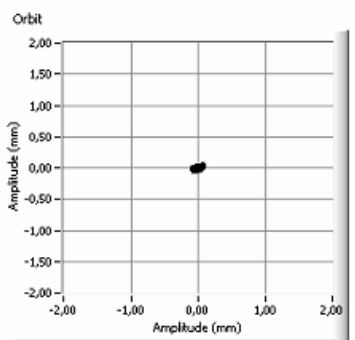

$55 \mathrm{~Hz}$

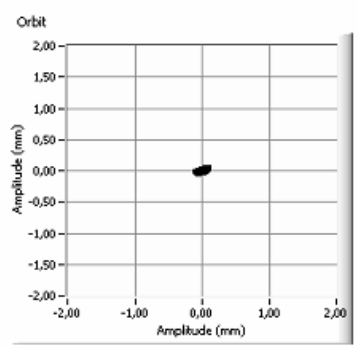

$60 \mathrm{~Hz}$

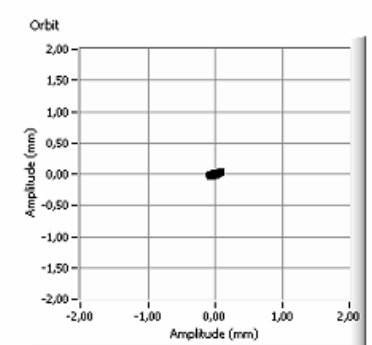

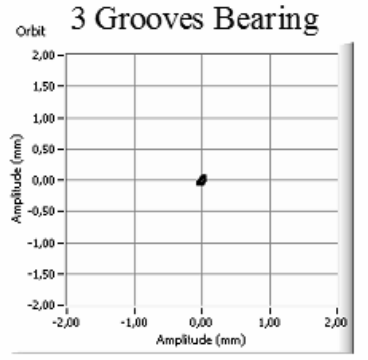
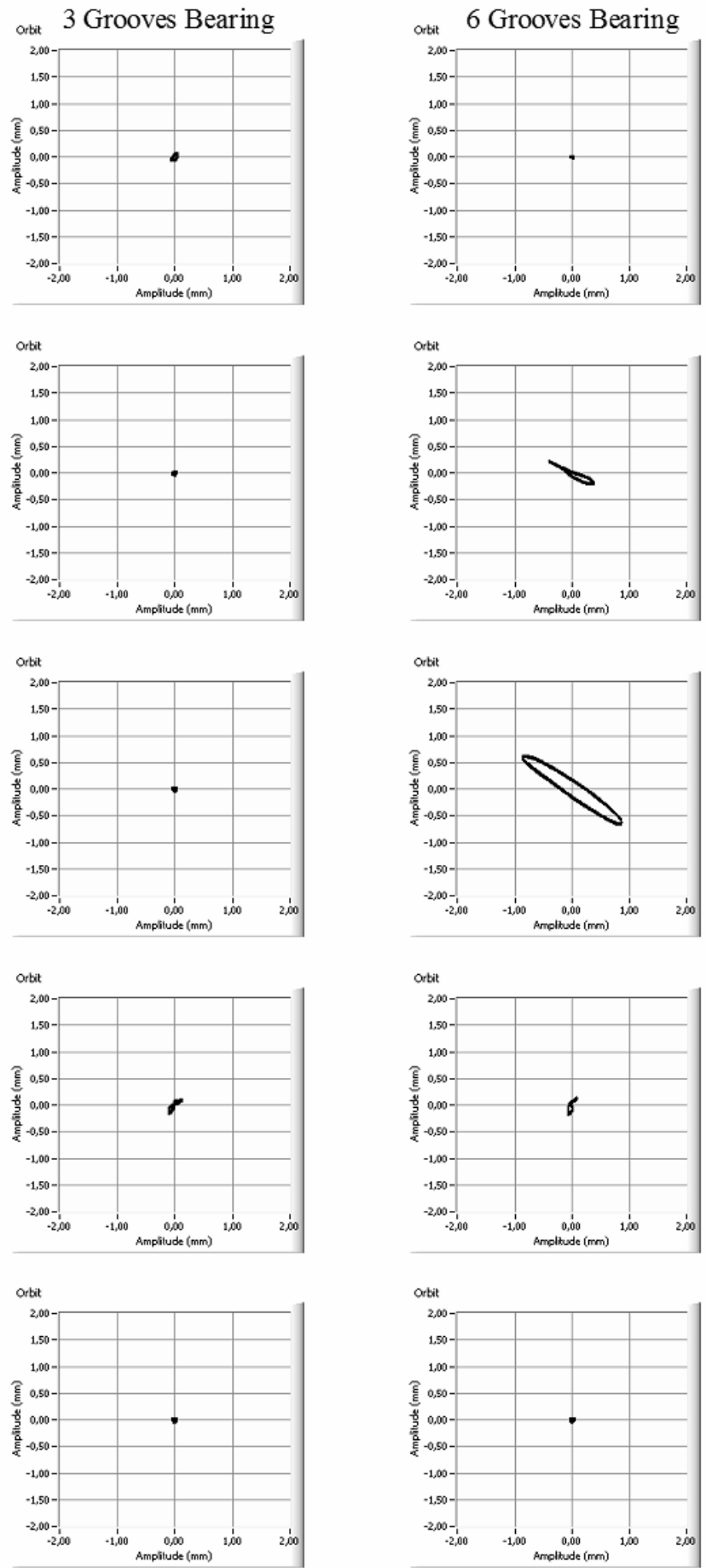

Fig. 9. Results - Orbit (continuation) 

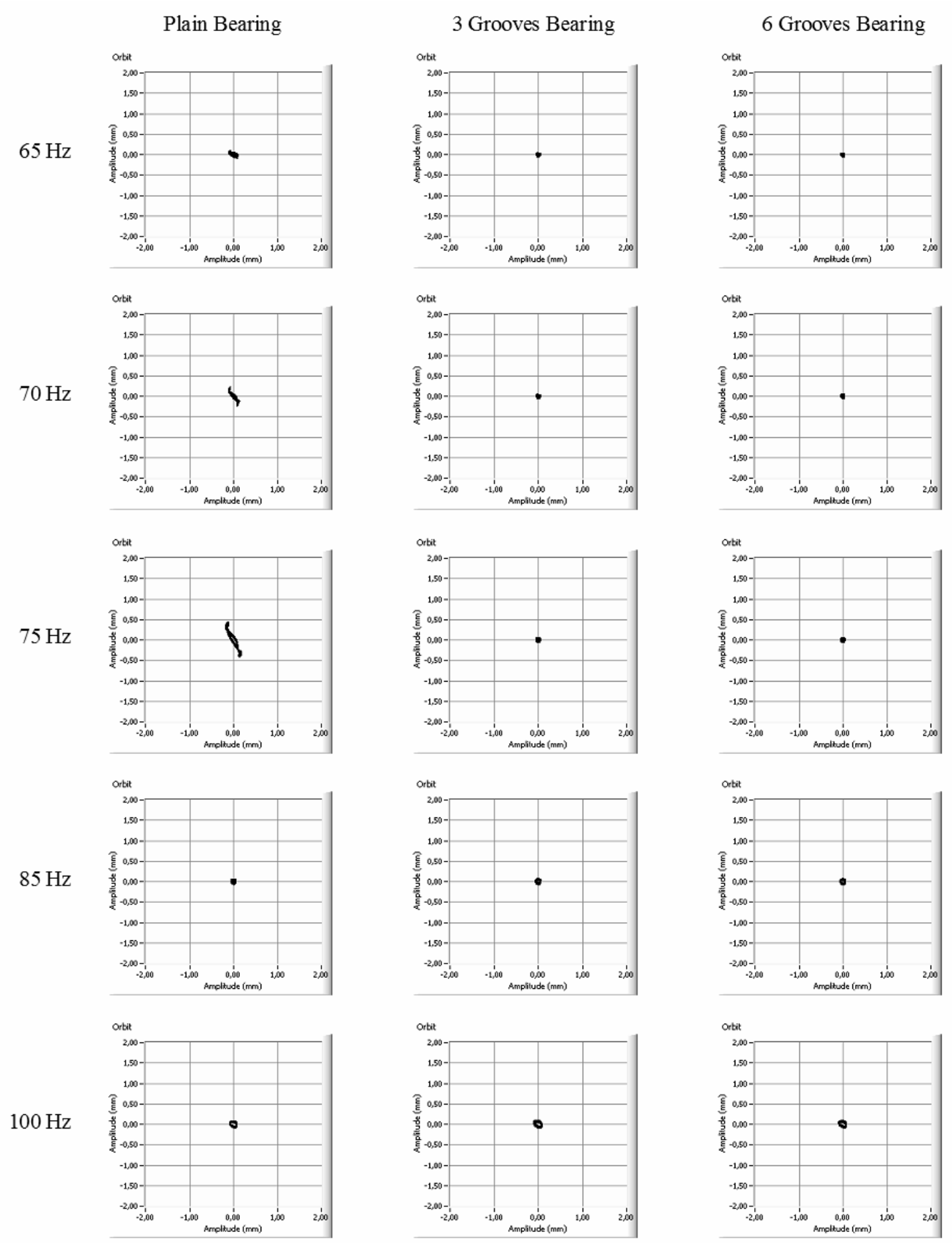

Fig. 10. Results - Orbit (continuation). 
$25 \mathrm{~Hz}$
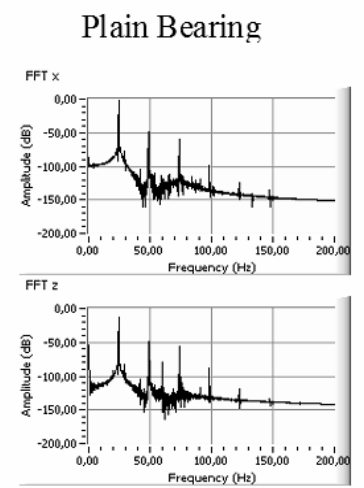

$35 \mathrm{~Hz}$
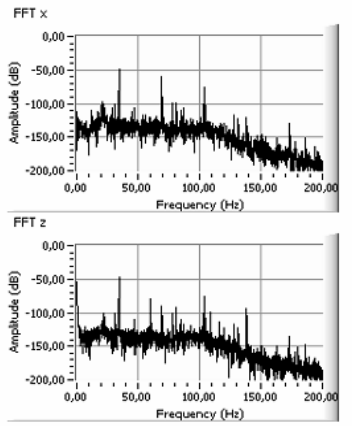

$45 \mathrm{~Hz}$
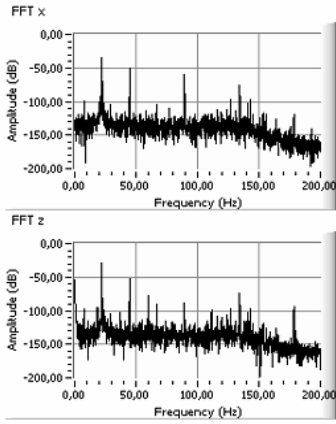

$50 \mathrm{~Hz}$
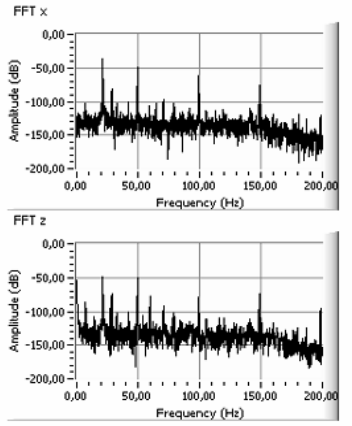

3 Grooves Bearing
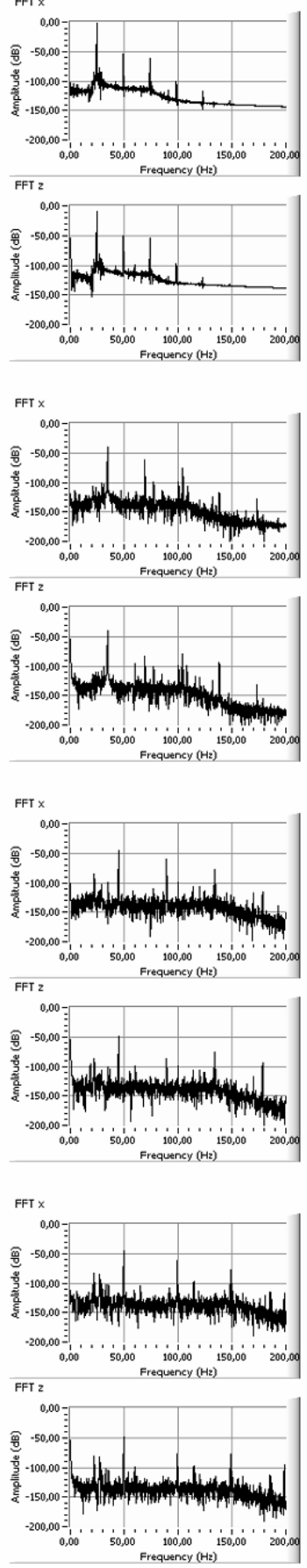

Fig. 11. Results - FFT.
6 Grooves Bearing
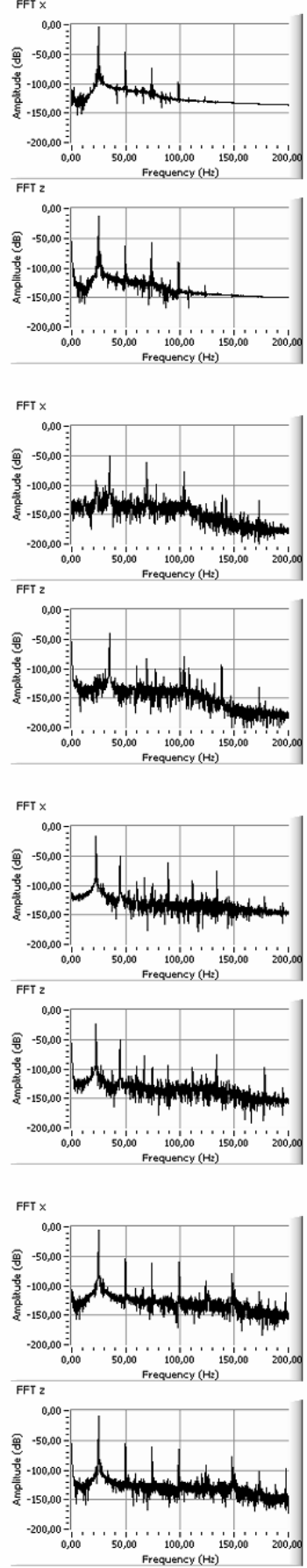
$55 \mathrm{~Hz}$

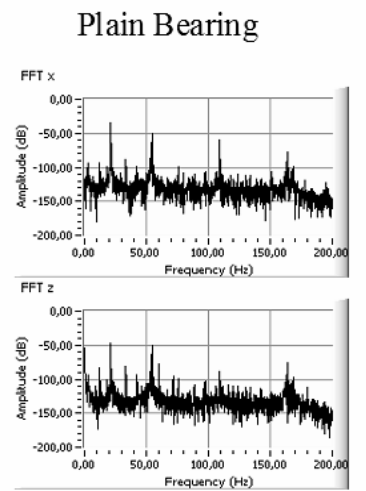

FFT $x$

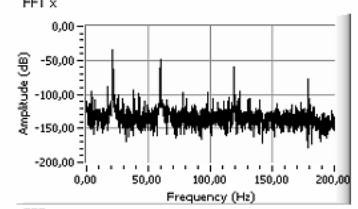

$60 \mathrm{~Hz}$

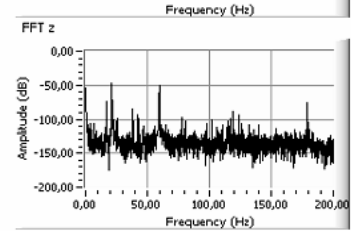

FFT $x$

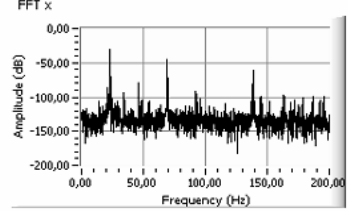

$70 \mathrm{~Hz}$
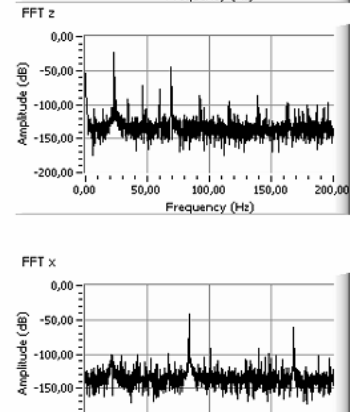

$85 \mathrm{~Hz}$

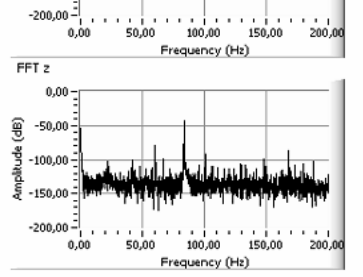

3 Grooves Bearing

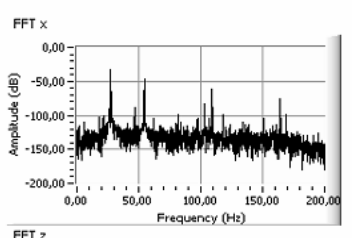

FFT 2

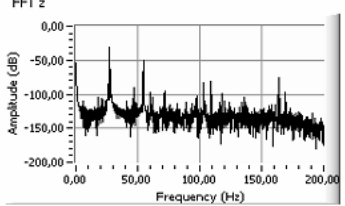

FFT X
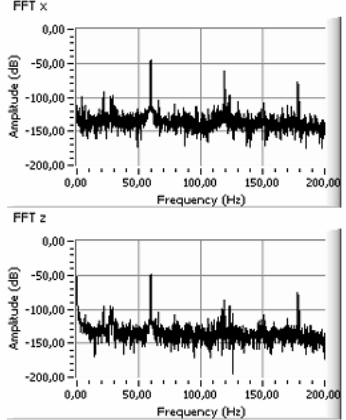

FFT $x$
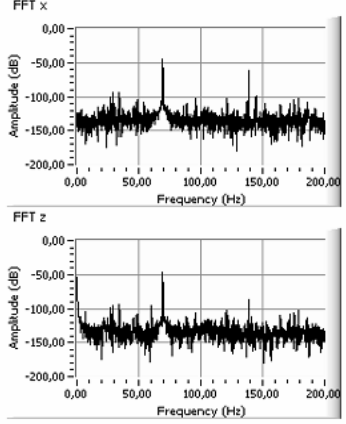

FFT $x$

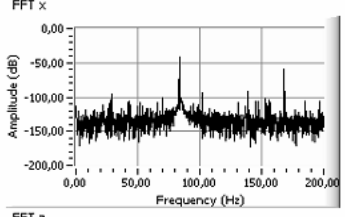

FFT 2

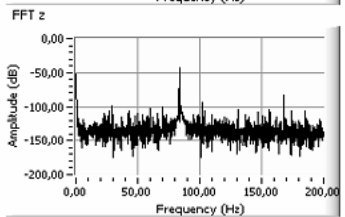

6 Grooves Bearing

FFT

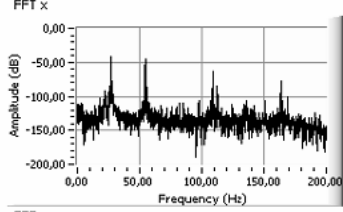

FFT 2

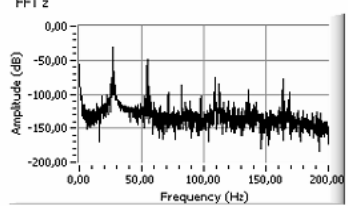

FFT $x$
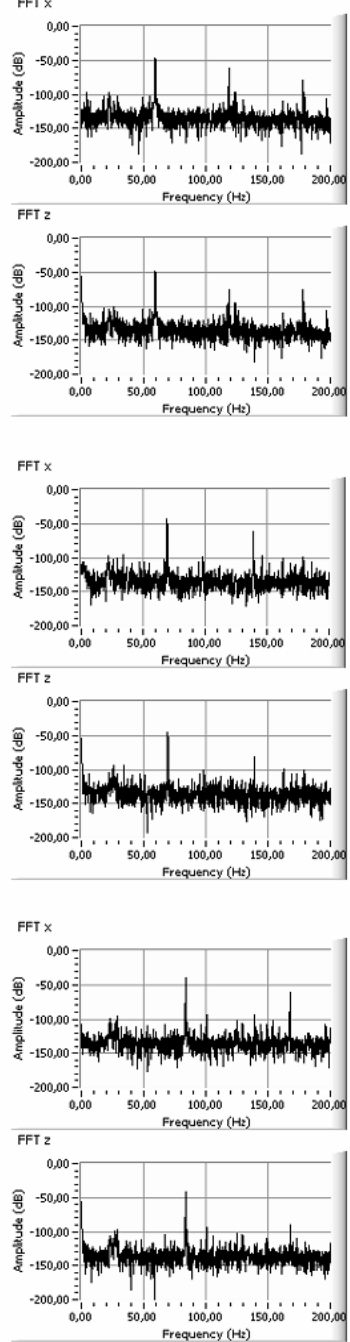

Fig. 12. Results - FFT (continuation). 
Plain Bearing

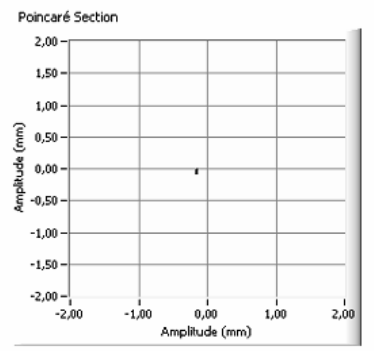

$20 \mathrm{~Hz}$

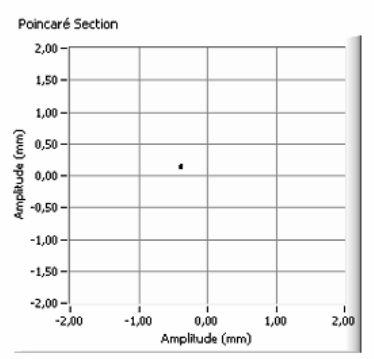

$30 \mathrm{~Hz}$

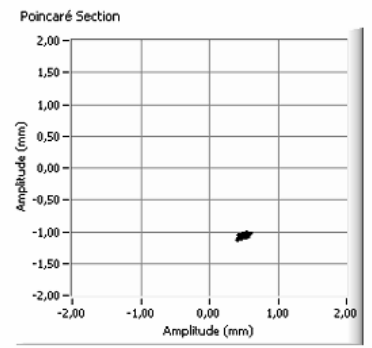

$40 \mathrm{~Hz}$

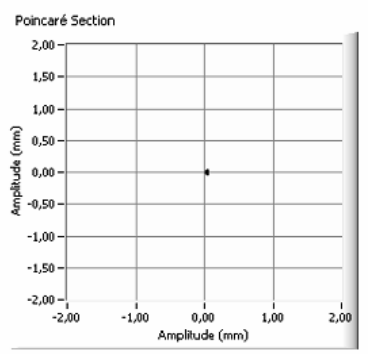

$45 \mathrm{~Hz}$

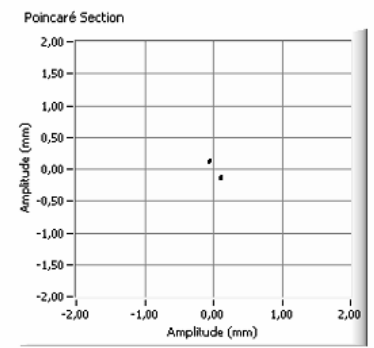

\section{Grooves Bearing}
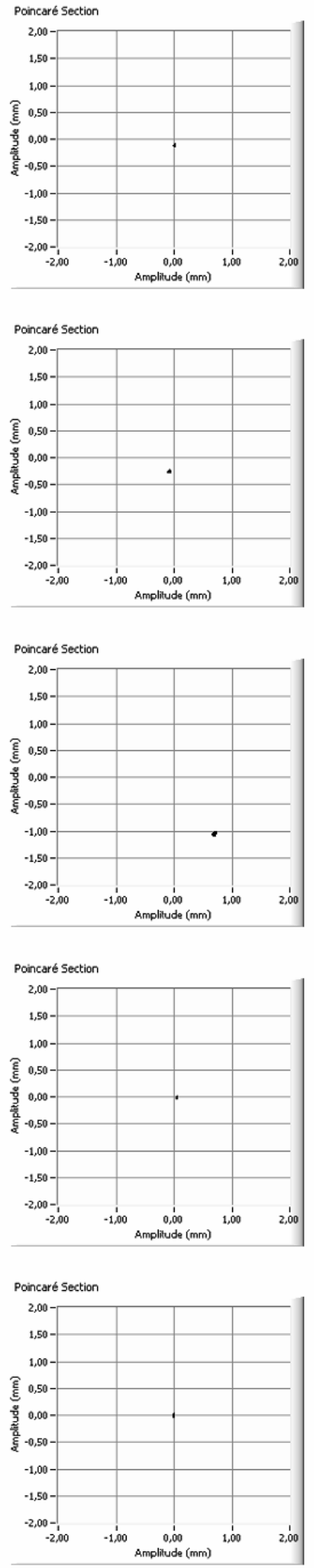

Fig. 13. Results - Poincaré map.

\section{Grooves Bearing}
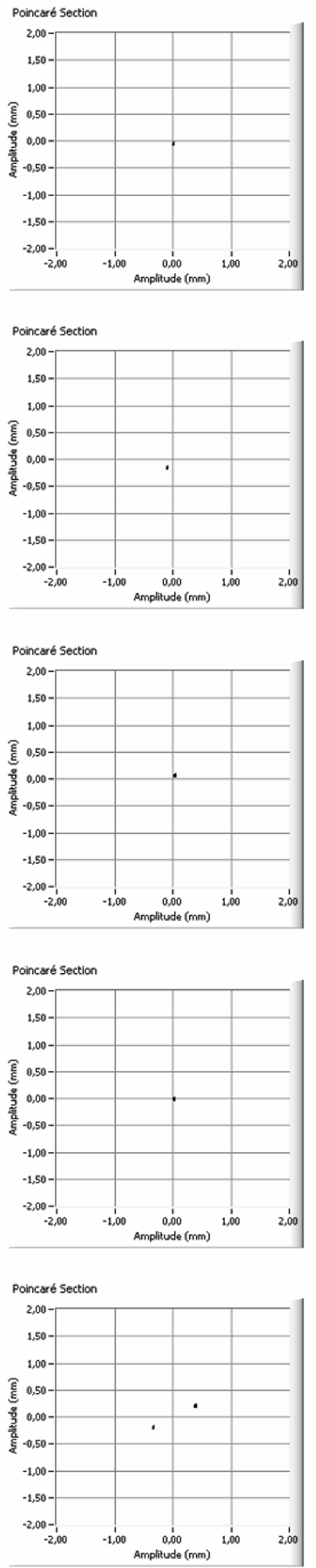
$50 \mathrm{~Hz}$

Plain Bearing

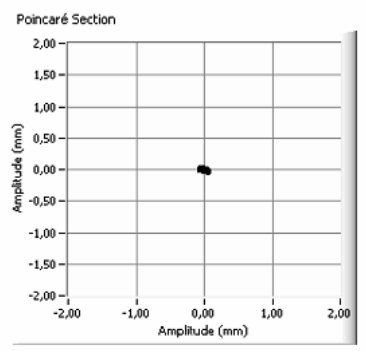

$55 \mathrm{~Hz}$

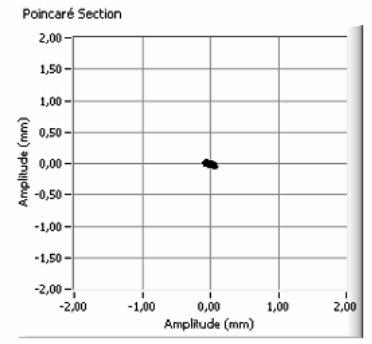

$60 \mathrm{~Hz}$

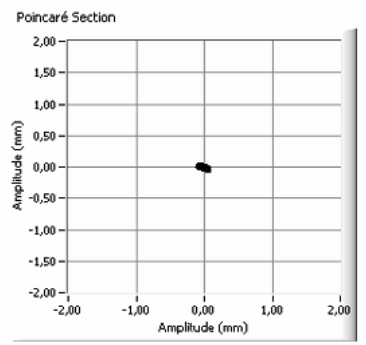

$65 \mathrm{~Hz}$

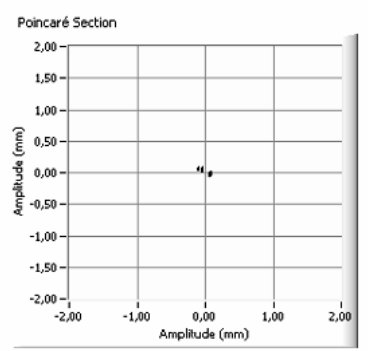

$70 \mathrm{~Hz}$

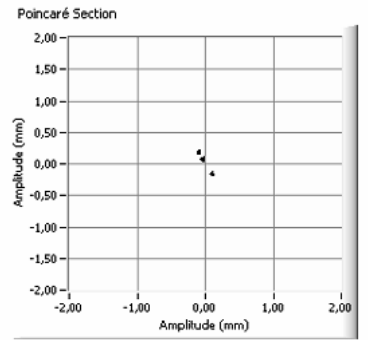

3 Grooves Bearing
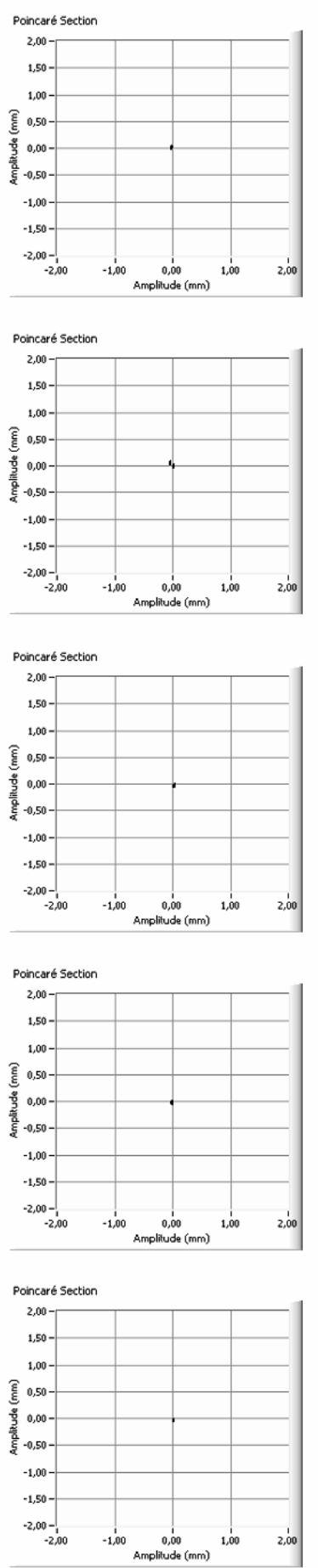

6 Grooves Bearing
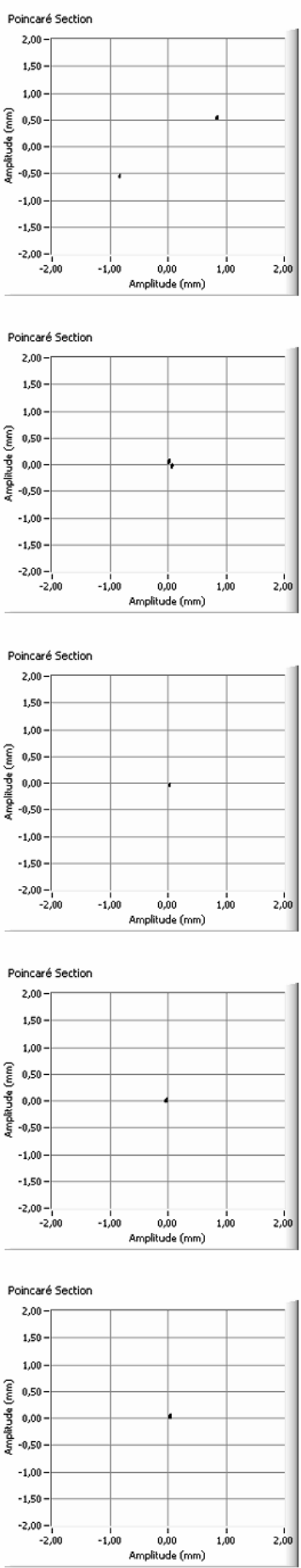

Fig. 14. Results - Poincaré map (continuation). 
Plain Bearing
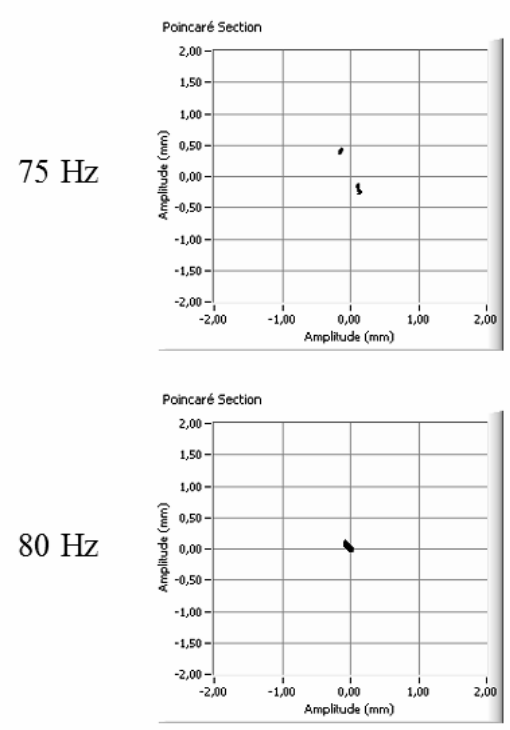

$80 \mathrm{~Hz}$

$75 \mathrm{~Hz}$

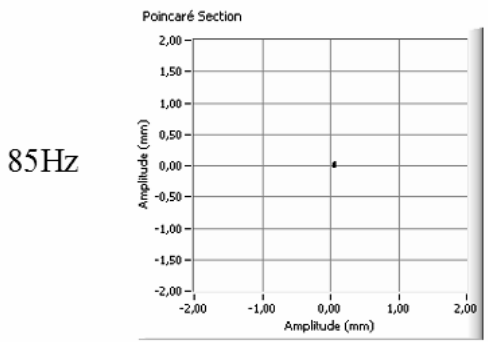

3 Grooves Bearing
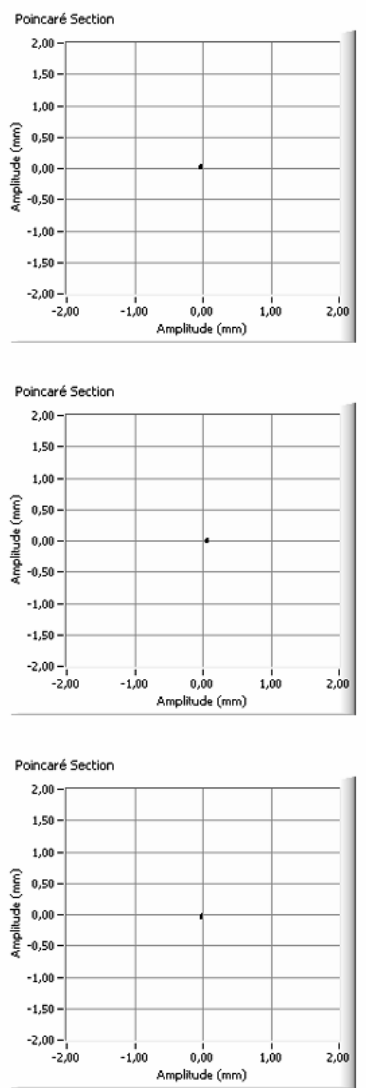

6 Grooves Bearing
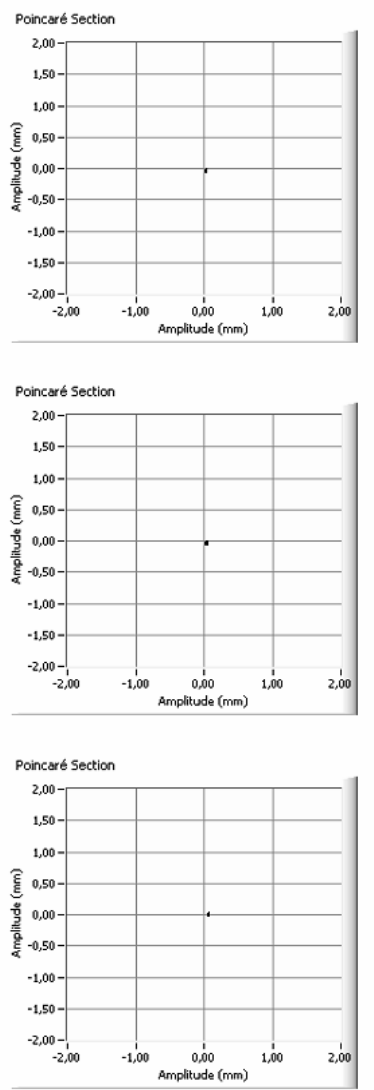

Fig. 15. Results - Poincaré map (continuation).

$75 \mathrm{~Hz}$. Also, here is a particularity about this case: from $65 \mathrm{~Hz}$ to $75 \mathrm{~Hz}$ the Poincare section presents three points instead of the two points presented in the other maps. This coincides with the rotational speeds where the oil whirl is noticeable.

\section{Conclusions}

This paper verified the influence of journal bearing axial grooves on the dynamic behavior of horizontal rotors. Three journal-bearing models, with different geometries, were used in order to compare the results between them, working with the rotor at several speeds (from $5 \mathrm{~Hz}$ up to $100 \mathrm{~Hz}$, in steps of $5 \mathrm{~Hz}$ ). The first model was a simple plain bearing and the others semi-circular axial grooved journal bearings (one with 3 grooves and another with 6 grooves).

A pressure field mathematical model was also used to show the theoretical difference between the oil film behaviors inside the bearings, but it was not yet possible to measure the real pressure field in the experimental cases. However, the differences between the models were experimentally noticed.

In addition to some classical signal analyzing tools, as the orbit analysis and the FFT analysis, this work also brings the use of a non-linear tool to analyze the rotor's behavior: the Poincar é map analysis.

Considering the results, looking at the particular behavior of the rotors, it is reasonable to say that the use of each journal bearing generates a different condition, but with very similar aspects. In all the cases, it is possible to observe the effects of oil whirl. However, the plain journal bearing use presents the greatest range of velocities where it is 
possible to see the influence of the oil whirl in the rotor behavior, as expected, especially in the orbit shape and in the bifurcations presented at the Poincaré map.

The oil whirl and oil whip phenomena generally happen when the lateral shift in the shaft is not big enough to stabilize the oil film. So, under certain conditions the oil film becomes unable to balance the shaft dynamic forces and allows the self exciting vibration that characterizes these phenomena. Generally, this happens in vertical rotors, or in horizontal ones with low weight. In heavy horizontal rotors, the system weight gives the rotor shaft a strong eccentricity from the bearing center that permits the system stabilization. Considering this fact, it points out that the rotor used in this work is light weighted.

The use of grooved journal bearings provides a more stable condition to the rotor operation. When the 3 axial grooved journal bearing was used, in only one rotational speed $(50 \mathrm{~Hz})$ it was possible to see the oil whirl influence in the rotor behavior. The grooves presence inside the bearings, considering the simulated model, generates some low pressure areas and high pressure peaks that stabilize the system with their own weight. However, it does not seem to change the rotor physical characteristics, as the system stiffness.

Nevertheless, when the 6 axial grooved journal bearings were used, another fact occurred. The unstable condition appeared at a rotational speed range greater than when the 3 axial grooved journal bearings were used (even so, were it is possible to notice the oil whirl phenomenon, in the plain journal bearing, the rotational speed range is broader). Beside that, even without the oil whip occurrence, in this case, the sub-harmonic influence was the greatest, as it can be observed when the rotor reaches $50 \mathrm{~Hz}$ (near twice the first natural frequency). The sub-harmonic becomes so outstanding that the rotor behaves as it was working near the first natural frequency.

The low pressure areas and high pressure peaks generated by the grooves presence in certain way stabilizes the system in this case, reducing the number of rotational speeds where the oil whirl is noticeable, when compared to the plain journal bearing, but the forces deriving from this pressure variation excite the rotor, inducing it to a very particular condition similar to the oil whip. So, in this particular case, the use of six grooves in the journal bearing does not improve the rotor stability as the three grooved journal bearings use.

The continuity of this work can bring new evidences of this unstable behavior and can help with a mathematical model to simulate some instability problems or the rotor working with different types of journal bearings. A nonlinear approach can help to understand the phenomena as well, considering the non-linear nature of the forces that act in the rotor under these conditions, as used here with the Poincaré map. These non-linear tools can develop the rotordynamic signal analysis and the numerical simulation of particular phenomena as the oil whirl and oil whip.

\section{Acknowledgement}

The authors would like to thank Ranny Nascimento, Anderson Pereira and F ábio Frade.

\section{References}

[1] M.V.G.S. Abrantes and M.A.C. Michalski, Projeto e Construção de uma Bancada Experimental para Estudos em Dinâmica de Rotores Horizontais, Graduation Final Project, EE - UFRJ, Rio de Janeiro, RJ, Brazil, 2002.

[2] D. Childs, Turbomachinery Rotordynamics - Phenomena, Modeling, and Analysis, John Wiley and Sons, 1993.

[3] D. Childs, H. Moes and H. van Leeuwen, Journal Bearing Impedance Descriptions for Rotordynamics Applications, Transactions of ASME, Journal of Lubricant Technology (April 1977).

[4] G. Genta, Vibration of Structures and Machines - Practical Aspects, Third Edition, Springer, 1999.

[5] R.G. Kirk and E.J. Gunter, Short Bearing Analysis Applied to Rotor Dynamics - Part I: Theory, Transactions of ASME, Journal of Lubricant Technology (January 1976).

[6] M. Lalanne and G. Ferraris, Rotordynamics Prediction in Engineering, Second Edition, John Wiley and Sons, 1998.

[7] M.A. Meggiolaro, Modelagem de Mancais Hidrodinâmicos na Simulação de Sistemas Rotativos, M.Sc. Thesis, Mechanical Engineering Department, PUC-Rio, 1996.

[8] A. Muszynska, Whirl and Whip - Rotor/Bearing Stability Problems, Journal of Sound and Vibration 110(3) (1986), 443-462.

[9] M.F. Spots, Design of Machine Elements, Fourth Edition, Pretice-Hall, 1984.

[10] M. Tanaka, Journal Bearing Performance Under Starved Lubrication, Tribology International 33 (2000), $259-264$.

[11] J.M. Vance, Rotordynamics of Turbomachinery, John Wiley and Sons, 1988. 

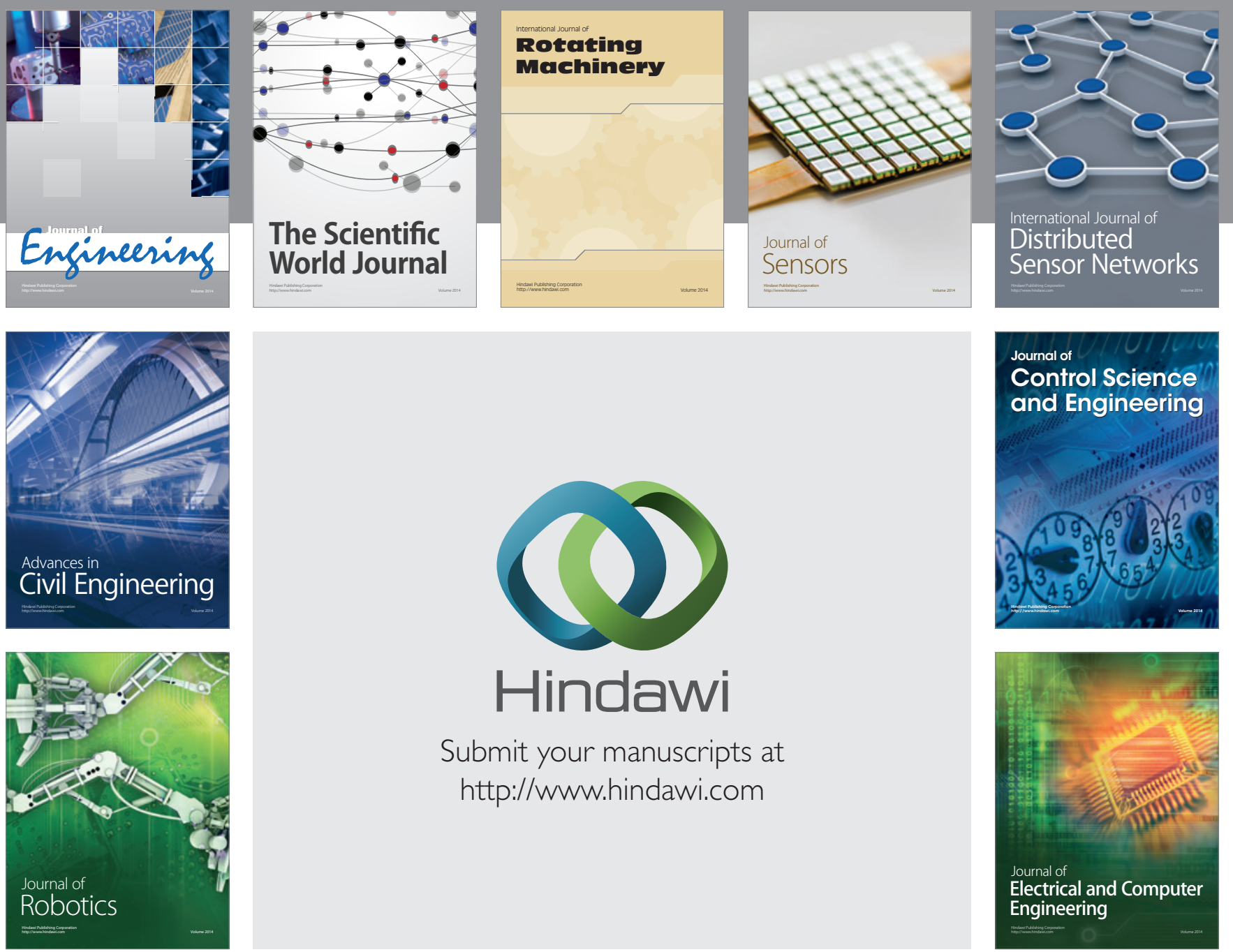

Submit your manuscripts at

http://www.hindawi.com
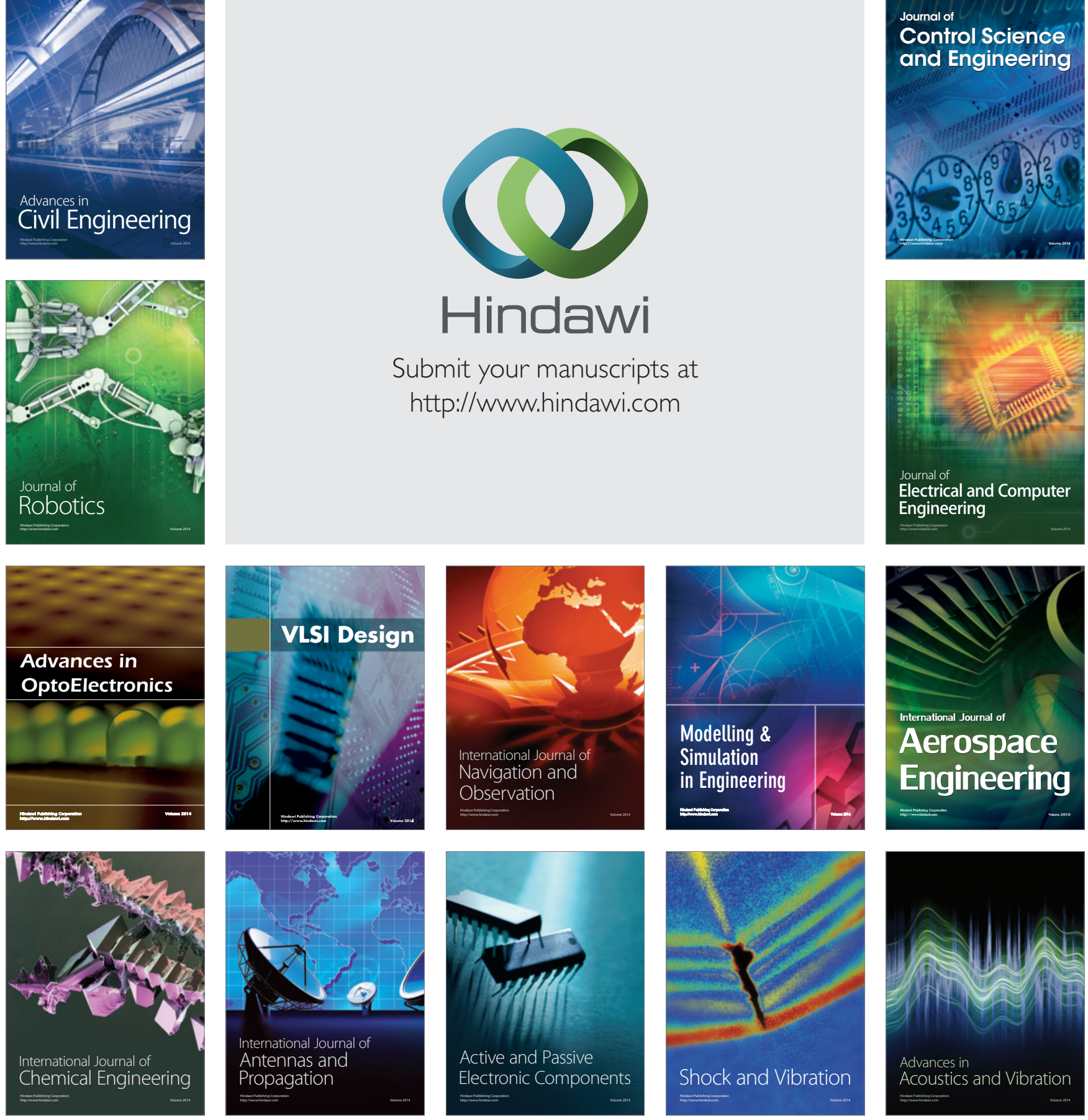